\title{
Nodular Opacity
}

National Cancer Institute

\section{Source}

National Cancer Institute. Nodular Opacity. NCI Thesaurus. Code C124062.

A radiologic finding indicating the presence of a solitary, round, circumscribed shadow in the lung on chest $\mathrm{x}$-ray. 